\title{
Static and dynamic testing of tendons
}

\author{
Naj Aziz ${ }^{1 *}$, Saman Khaleghparast ${ }^{1}$, Sina Anzanpour ${ }^{1}$, Alex Remennikov ${ }^{1}$, Ali \\ Mirzaghorbanali ${ }^{2}$ \\ ${ }^{1}$ University of Wollongong, Wollongong, Australia \\ ${ }^{2}$ University of Southern Queensland, Toowoomba, Australia
}

\begin{abstract}
Underground support system using tendons has been one of the significant achievements in Civil and Mining engineering endeavours in facing challenges of ground control. However, shear failure of rock bolts is still one of the least monitored phenomenon in underground excavations with respect to seismic events. The understanding of the performance of rock bolts under dynamic loading condition requires a great deal of research. A series of tests were undertaken utilising a drop hammer mass of $600 \mathrm{Kg}$ from a maximum height of $3.7 \mathrm{~m}$ over concrete blocks in the double shear box with chemical resin encapsulated a rock bolt to investigate the performance of rock bolts under dynamic shear load. Load cells, displacement laser and high speed camera were used to monitor the test. Results from the data analyses are presented in the form of displacement, hammer mass drop velocity, acceleration and force variation with time for all components involved in each test. The time factor was found to contribute $30 \%$ of the shear load in static testing in comparison with dynamic; In particular, the force-displacement curve and energy absorption for the reinforcement system are presented to examine the performance of rock bolts and conclusion drawn.
\end{abstract}

\section{Introduction}

Characterisation of the strength of rock bolts and cable bolts for underground mining is generally based on tensile and shear strength. These two properties are determined by static testing, however and in recent years, many tests have been reported on dynamically (Player, 2004, Plouffe, et al., 2008), The current thinking of ground reinforcement in underground mining has moved away from emphasising solely on ground support. The increased rate of mining development, production and mine operator safety is continuing to gain equal importance with ground support and its resilience in adverse mining environment. The prospect of ground seismicity and rock bursts requires special attention on support infrastructure installation effectiveness, both in metal and coal mining. The Beaconsfield gold mine collapse, in Tasmania, triggered by seismic activity and pressure bursts at Austar

*Corresponding authors: naj@uow.edu.au 
coal mine, due to high levels of stress contribution caused by the presence of disturbed structural geology in the region with fault zones and shear zones as reported by Galvin and Hebblewhite (2016) are stark reminder of the challenges that mines are faced with in adverse conditions. This necessitates the need for credible research on ground support under these adverse conditions under both static and dynamic conditions. The need for effective research on ground support credibility is of equal importance to the collapse of the ground due to gas outbursts, which are more common in coal mines worldwide and are well documented (http://miningst.com/category/coal-mine-outburst/). It is obvious that dynamic testing of tendons appears to focus on axial tensile testing and no reporting has been made on dynamic testing in shear. Tendon shear strength characteristics are important when shear deformation occurs across joints and shear zones, which are the weakest zones in ground structure that normally yields readily to rock burst or any other seismic activity. This paper describes the method of dynamic shear testing of tendons using double shear apparatus and compares the findings with static method.

\section{Methodology}

The methodology used in this study will utilise testing of tendons by double shear tests.

\subsection{Double Shear Box}

Aziz, et al., (2019) described four different types of the double shear boxes for undertaking research on tendon technology. They are;

- $\quad$ MK-I DSB; $600 \mathrm{~mm}$ long consisting of a $300 \mathrm{~mm}$ long prism block, sandwiched between two $150 \mathrm{~mm}$ side cubes. This rig is used mostly for testing small diameter rebar up to $24 \mathrm{~mm}$ in diameter as well as FG dowels.

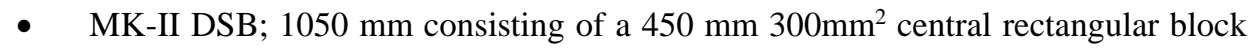
sandwiched between $300 \mathrm{~mm}^{3}$ blocks

- $\quad$ MK- III DSB Friction free rig; a modified MK-II rig with lateral truss system consisting of four open channels braces attached to two $30 \mathrm{~mm}$ thick plates to maintain confinement for friction free shearing of the tendon, by maintain a constant gap between the joint planes of the concrete blocks

- $\quad$ MK- IV DSB (Naj’s box); a $300 \mathrm{~mm}$ diameter circular shear box of $450 \mathrm{~mm}$ long central cylinder sandwiched between two $300 \mathrm{~mm}^{3}$ blocks.
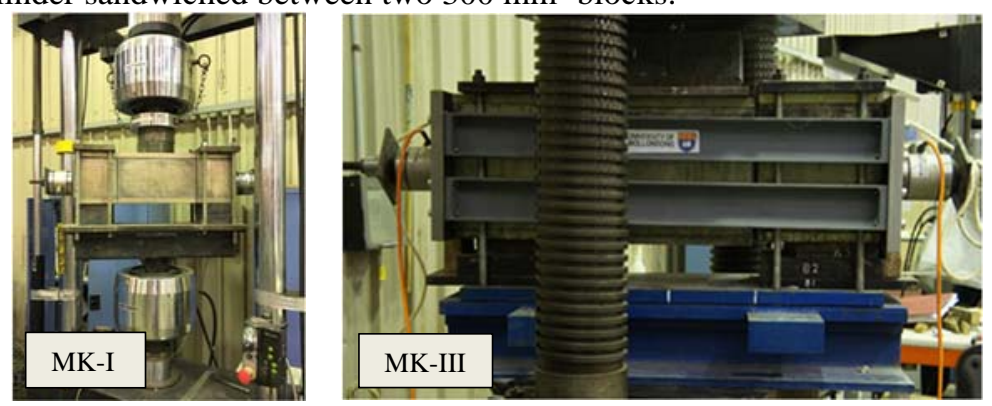

Fig. 1. MK-I and MK-III Double Shear Boxes

Two sizes of the double shear box were used in this study, MK-I and MK-III double shear boxes. These selected rigs were based on the comparative studies undertaken under both static and dynamic conditions as reported in this paper. Fig. 1 shows both types of double shear boxes used for static testing of various tendons. MK-I DS box was used for solid rock bolting study while MK-III was used for testing of cable bolts of varying shear failure 
strength. MK-III DSB was developed for testing of tendons for friction free sheared joint faces; with the near total applied shearing load being spent on cable bolt shearing.

\subsection{The High Capacity Impact Machine}

The drop hammer test method simulates a high energy impact load condition similar in amplitude and velocity to a rock burst event. Therefore, in this study, the drop hammer was employed to examine the impact and shear performance of conventional rock bolts and cable bolts. Fig. 2 shows schematic and general view of the drop hammer load impact rig. The core of the test rig is the free-fall hammer having $592 \mathrm{Kg}$ weight that can be dropped from a maximum height of $3.7 \mathrm{~m}$, or equivalent to the drop velocity up to $7.5 \mathrm{~m} / \mathrm{s}$. A $1200 \mathrm{kN}$ dynamic load cell (Type Interface Model 1200) is attached to the hammer that can measure the force applied to the medium at the time of the impact. The drop hammer test method simulates a high energy impact load condition similar in amplitude and velocity to a rock burst event.

As the hammer falls, a laser gate triggers the load cell which allows data to be recorded by a data acquisition system. The data collected is transferred to a computer where the result can be analysed. High speed camera Fastec trouble-shooter was utilised to capture the highenergy impact between the drop hammer and the MK-I shear box with high accuracy. This allows an accurate analysis of the displacement of the central block during the shearing load over the period of time. Shearing displacement of the central block was also monitored through utilising a laser placing underneath the central block.

The MK-I set up box was seated on a U shape beam. The beam was placed between two based plates, which were anchored to the ground. The outer frames of the shear box were then clamped tightly with the base platform to avoid rotation of the blocks during drop loading impact. A laser was located beneath the $U$ shape beam on the floor to capture the displacement of the central block during the experiment. To ensure the load from the drop hammer distributed evenly over the central block also prevent damaging to the box, a $30 \mathrm{~mm}$ thick plate was used on the top of the central block covered with a $3 \mathrm{~mm}$ thick plastic rubber. The potential height for each specimen was calculated based on the absorbed energy in static test calculated from the area under the Load-displacement curve.
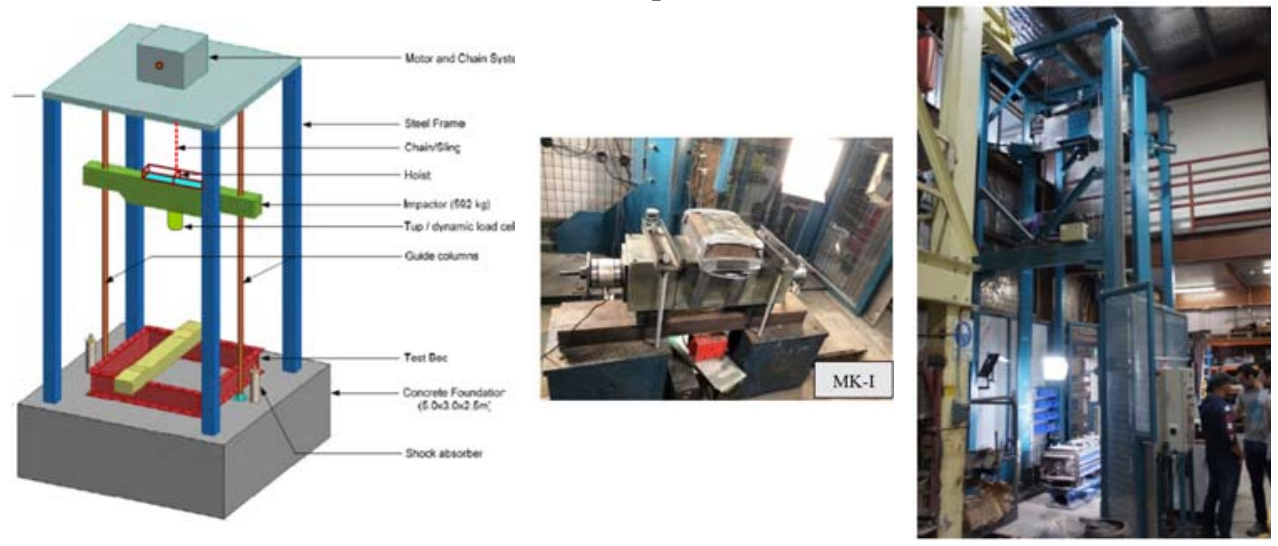

Fig. 2. Drop hammer test and MK-I set up 


\subsection{Concrete block preparation}

For both box sizes the preparation of concrete blocks were cast in marine plywood moulds, although the steel frames of each box type could also be used satisfactorily. Two types of conduits were used to create holes for tendon insertion axially in each box and grouted. Three sizes of holes were created for shear testing, a $24 \mathrm{~mm}, 42 \mathrm{~mm}$ and $46 \mathrm{~mm}$ holes. For $24 \mathrm{~mm}$ hole in MK-I shear box, a $24 \mathrm{~mm}$ plastic conduit covered with $3 \mathrm{~mm}$ electrical wire wrapped around it placed in the small moulds to created holes up to $24 \mathrm{~mm}$ in diameter for the desired bolt installation and encapsulation and also for larger borehole a $35 \mathrm{~mm}$ solid steel rod with $6 \mathrm{~mm}$ diameter PVC wrapped around it was used to create $46 \mathrm{~mm}$ borehole. For larger MKIII diameter hole creation a $30 \mathrm{~mm}$ solid steel pipe with $8 \mathrm{~mm}$ diameter PVC wrapped around it was used to created $42 \mathrm{~mm}$ diameter hole.

Once mixed, the cement mortar, consisting of sand, cement, aggregate and water, was poured into each section of moulds. The mould was thoroughly covered with neutral grease for ease of concrete and steel pipe release. Once poured concrete was thoroughly vibrated using a hand vibrator and trawled to level and smoothen. Fig. 3 shows general views of both MKI and MKIII double shear boxes.
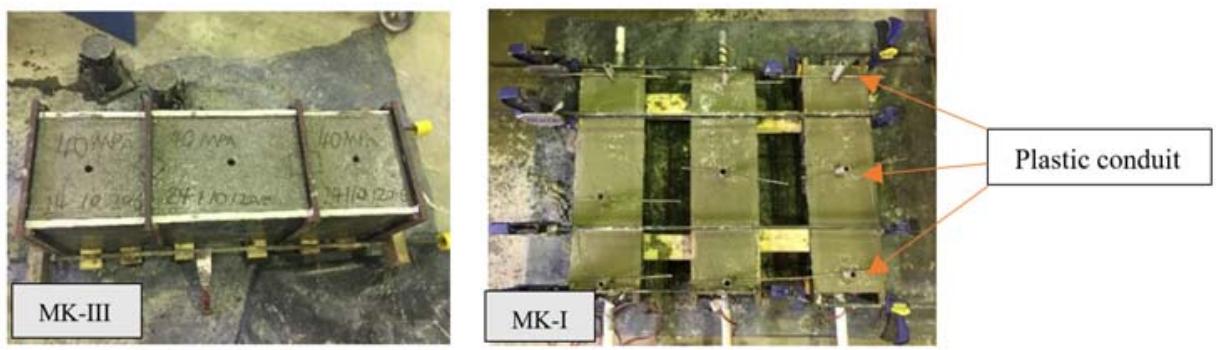

Fig. 3. Casting the concrete blocks

Three small plastic conduits were inserted perpendicularly to reach the middle laterally placed conduit in the blocks as shown in Fig. 3. Once the concrete was semi hardened, the conduit was removed from the centre of the blocks and the coaxial wire or tube was pulled out, leaving the hole wall with the image of the printed groove surface. The concrete was left for 24 hrs to set and then removed and placed in a water bath for 30 days to cure. The concrete strength for this study was confirmed from UCS tests on $200 \mathrm{~mm}$ and $100 \mathrm{~mm}$ diameter concrete cylinders prepared during concrete pour. Two types of rock bolt were examined for this study. 18mm DSI smooth rock bolt and $18 \mathrm{~mm}$ Jennmar ribbed profile rock bolt. The double shear test also extended to include $15 \mathrm{~mm}$ diameter 7 wire cable bolts. A $1400 \mathrm{~mm}$ long rock bolt with $300 \mathrm{~mm}$ thread on both ends was fixed into the concrete blocks using Minova Stratabinder HS cementitious grout with water: cement ratio of 0.4 for the encapsulation. Prior to grouting, pretension load was applied through tightening simultaneously the nuts on the both ends with wrench. Load was monitored using $150 \mathrm{kN}$ load cells attached to data-taker. Once the pretension load reached, the sample left for $5 \mathrm{~min}$ allowing for relaxation and stabilization of the pretension load and then filled with grout. The specimen was left for seven days to cure. The specimen was then mounted in a steel frame shear box fabricated for this purpose. The testing apparatus consisted of a series of $20 \mathrm{~mm}$ thick steel plates secured by 34, $300 \mathrm{~mm}$ screws. A base platform that fitted into the bottom ram of the Instron Universal Testing Machine, capacity $50 \mathrm{kN}$, was used to hold the MKI shear box. Two steel blocks with a thickness of $55 \mathrm{~mm}$ were placed beneath the two-outer entity of the concrete blocks to allow for central block to travel vertically as $110 \mathrm{~mm}$ when shearing load is applied. The outer entity of the shear box was then clamped tightly with the base platform to avoid rotation of the blocks during shear loading. The applied displacement load on central block was set to the rate of $1 \mathrm{~mm} / \mathrm{min}$ and was controlled during the test process. Moreover, the vertical movement of the central block was limited into $100 \mathrm{~mm}$ for 
each test. The compression machine embedded recording system was utilized to record the shear load, shear displacement and the axial load by data-taker hooked up to the load cells. The shearing load, displacement and axial load was monitored during loading throughout the test and it was possible to be visually seen on the computer screen.

\subsection{MK-III test sample preparation}

Individual concrete blocks were first mounted on the carrier base plate. The outer blocks were laid on solid steel plates while the central block was supported with adjustable height and removal metal base. The minimum block stand height was in the order of clearance height of $100 \mathrm{~mm}$. A short $50 \mathrm{~mm}$ diameter PVC tubes were inserted between the central hole ends to bridge the gap across concrete joints and allow the flow of the grout in the hole. This is further reinforced with glued circular compressible foam ring packers, to ensure no leakage occurring in gaps between concrete blocks during cable grouting. Meanwhile, a lateral truss system was mounted axially across the assembled blocks to maintain and hold concrete blocks in a set place and prevent the adjacent concrete joint faces coming in contact with each other during pretensioning and shearing stage. The trust system consisted of two lateral $9 \mathrm{~mm}$ thick opened channel steel braces, which were mounted on each side of the shear box and screwed on two $30 \mathrm{~mm}$ thick side plates to prevent subjecting normal load on concrete blocks during shearing. Once the cable is inserted in the concrete frame and pre-tensioned to the required axial load, the cable as fitted with load cells at both ends and plates, followed by insertion of tightening barrel and wedges. The cable was then pre-tensioned using BlueHealer tensioner to the recommended tension load. The pre-tension load on cable bolt was monitored by load cells connected on a data taker and computer. When the pre-tension load reached the required load, it was maintained loaded for several minutes and the hydraulic jack was then removed after the load to let the cable grouting to harden and ready shear testing at a predetermined grout aging period. This was the followed by grouting using Minova Stratabinder HS grout of the cement/ ratio of 0.4. The grout was then injected on to the install cable bolt hole poured through vertical connecting holes cast on the blocks and left to harden/set. The double shear assembled box was them covered with the top steel plates, clamped and tightened to a minimum of $40 \mathrm{kN}$ for effective confinement. To avoid rotation and toppling of the side block during shear loading, eight steel bars were inserted into the base platform plate and to hold them firm on the base platform as shown in Figure 4. A total of five rock bolts and a cable bolt were tested prior to proceeding to the drop hammer test. The results are shown in Table 1.

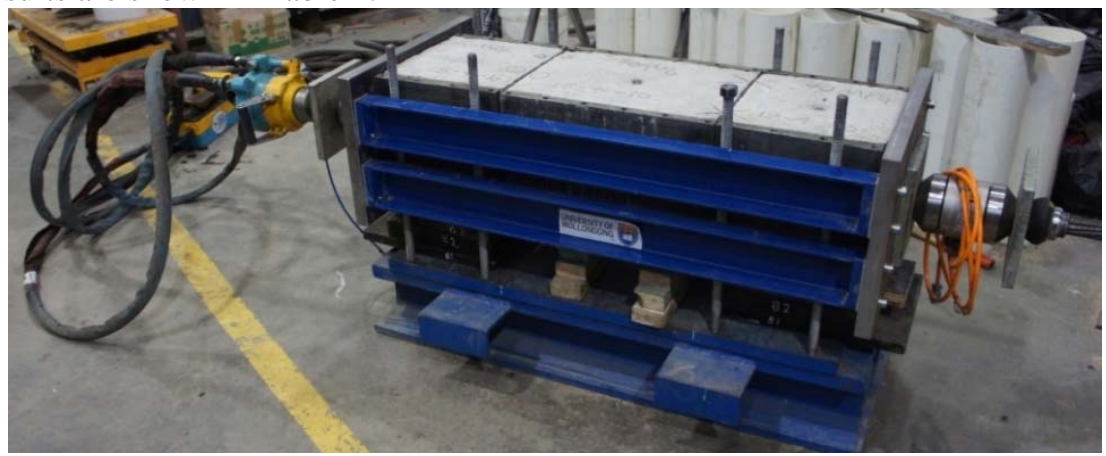

Fig. 4. MK-III Double Shear assembly 
Table 1. Results of static and dynamic tests carried out on rock bolts and cable bolts

\begin{tabular}{|c|c|c|c|c|c|c|c|c|c|c|c|c|c|}
\hline \multirow{3}{*}{$\begin{array}{l}\text { Test } \\
\text { No. }\end{array}$} & \multicolumn{7}{|c|}{ Test Properties } & \multicolumn{2}{|c|}{ Test Results } & \multicolumn{4}{|c|}{ Test Analysis } \\
\hline & \multirow{2}{*}{$\begin{array}{l}\text { Tendon } \\
\text { Type }\end{array}$} & \multirow{2}{*}{$\begin{array}{c}\text { Tendon } \\
\emptyset \\
(\mathrm{mm})\end{array}$} & \multirow{2}{*}{$\begin{array}{l}\text { Pretension } \\
\quad(\mathrm{kN})\end{array}$} & \multirow{2}{*}{$\begin{array}{c}\text { Borehole } \\
\emptyset \\
(\mathrm{mm})\end{array}$} & \multirow{2}{*}{$\begin{array}{c}\text { Drop } \\
\text { Height } \\
\text { (m) }\end{array}$} & \multirow{2}{*}{$\begin{array}{c}\text { Concrete } \\
\text { Strength } \\
\text { (MPa) }\end{array}$} & \multirow{2}{*}{$\begin{array}{c}\text { Internal } \\
\text { Confinement }\end{array}$} & \multirow{2}{*}{$\begin{array}{l}\text { Static } \\
\text { Load } \\
(\mathrm{kN})\end{array}$} & \multirow{2}{*}{$\begin{array}{c}\text { Dynamic } \\
\text { Load } \\
(\mathrm{kN})\end{array}$} & \multirow{2}{*}{$\begin{array}{c}70 \% \\
\text { Static } \\
\text { Load } \\
(\mathrm{kN})\end{array}$} & \multirow{2}{*}{$\begin{array}{l}\text { Effective } \\
\text { friction } \\
(\%)\end{array}$} & \multicolumn{2}{|c|}{$\begin{array}{c}\text { Absorbed Energy } \\
(\mathrm{kJ})\end{array}$} \\
\hline & & & & & & & & & & & & Static & Dynamic \\
\hline 1 & $\begin{array}{c}\text { Ribbed } \\
\text { Bolt }\end{array}$ & 18 & 3 & 24 & 2 & 40 & Yes & 324.2 & 230 & 227 & 70 & 11.26 & 7.88 \\
\hline 2 & $\begin{array}{c}\text { Smooth } \\
\text { Bolt }\end{array}$ & 18 & 5 & 24 & 1.5 & 40 & Yes & 332 & 227 & 232.5 & 68 & 10.57 & 7.12 \\
\hline 3 & $\begin{array}{c}\text { Ribbed } \\
\text { Bolt }\end{array}$ & 18 & 3 & 24 & 2 & 40 & Yes & 324.2 & 236 & 227 & 72 & 11.26 & 7.62 \\
\hline 4 & $\begin{array}{c}\text { Ribbed } \\
\text { Bolt }\end{array}$ & 18 & 5 & 24 & 2 & 40 & Yes & 342.8 & 200 & 240 & 58 & 13.07 & 8.55 \\
\hline 5 & $\begin{array}{c}\text { Ribbed } \\
\text { Bolt }\end{array}$ & 18 & 3 & 46 & 2 & 20 & NO & 270 & 160 & 189 & 59 & 13.51 & 8.0 \\
\hline 6 & $\begin{array}{l}\text { Plain } \\
\text { Cable }\end{array}$ & 15 & 5 & 42 & 2 & 40 & NO & 314 & 225 & 220 & 72 & 8.83 & 14.7 \\
\hline
\end{tabular}

\section{Results and analysis}

Table 1 lists the number of tests carried out in this programme of study. The table provides details of two different rock bolts and one cable bolt and their characteristics. Rock bolts and cable bolts were tested in different strength concrete blocks of 20, 40 and $60 \mathrm{MPa}$, encapsulated with Stratabinder grout. The peak static and dynamic double shear loads, as well as energy absorbed by the DST system are shown in Table 1. The absorbed energy of the system was calculated, based on the static test at the loading rate of $1 \mathrm{~mm} / \mathrm{min}$, by estimating the area underneath the load-displacement graph using trapezoidal rule, shown as shaded section in Fig.. The drop test is a more reliable simulation of the in situ rock burst since the seismicity and the rock burst occurs suddenly at a short duration, similar to the situation of free weight drop. The input energy can be adjusted by the drop height. Weight drop height was considered to be constant at $2 \mathrm{~m}$ to reduce the variable in the test.

A single impact load (SIL) was applied to each specimen. When the first SIL impacted the specimen, the specimen started to close-in laterally for 1-2 ms and then began to bounce back. The specimen started to accelerate vertically downwards when the rock bolt resistance exceeded the impact force with the middle block acceleration stopping within $10 \mathrm{~ms}$. Plastic deformation occurred when the dynamic load exceeded the elastic limit of the rock bolt. As a result of the impact load the load displacement with time graph, shown in Fig. can be divided into three stages. The initial stage (point1) is when the SIL contacted with the plastic rubber and compressed the rubber until the specimen started bearing the load. In this stage the velocity of the SIL decreased whilst the velocity of the specimen increased. This change is known as inertia effect and can be seen from the graph at the peak point (point 1). The second stage (point 2) occurs when both the SIL and the specimen move downwards together, which is clearly shown in the displacement graph. In this stage the rock bolt played an important role in resisting any changes, due to a dramatic stress changes. The last stage (point 3) occurred when the rock bolt ruptured because of the dynamic force induced by the SIL was greater than the bolt resistance force. 


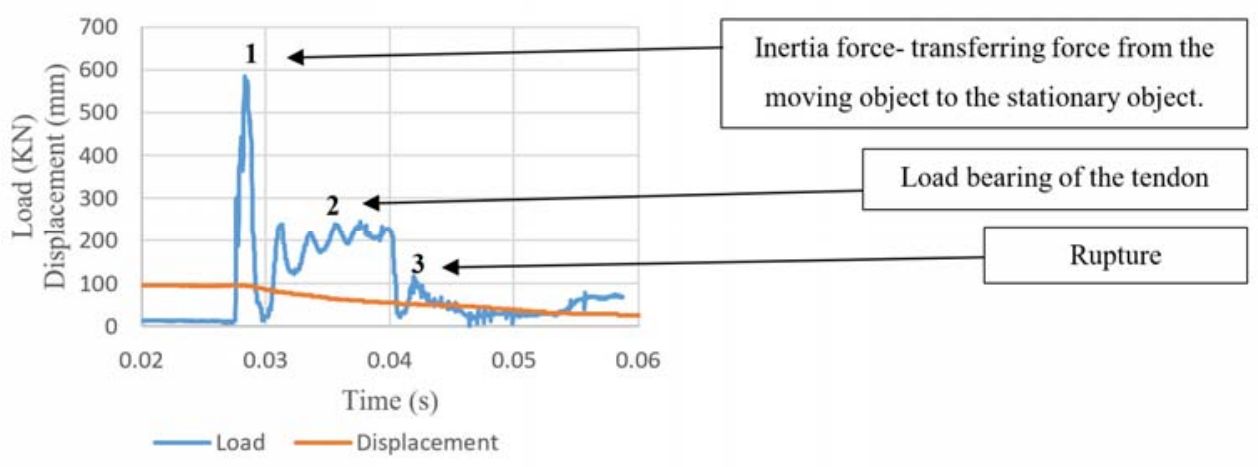

Fig. 5. Load and displacement graph vs. time in dynamic test of rock bolt

\subsection{Internal confinement}

Figure 6 illustrates effect of internal confinement on the performance of rock bolts in static and dynamic tests. The internal confinement of the concrete block contributes to increased concrete strength and stiffness, which minimises early concrete deformation around the tendon close to sheared joint faces, thus reducing concrete deformation depth at the hinge points by as much as $40 \%$. As can be seen in 6 , the slope of the graph with internal confinement is much steeper than no confinement graph, which means that the rock bolt is under greater shear stress than being in tension. Also the internal confinement prevents or minimises crack propagation axially along the sample, which indicates that the concrete will not fail early and the rock bolt eventually will fail in true shear rather than tension. Insufficient concert confinement would cause radial as well as axial cracking of the concrete blocks in the shearing zone, which would ultimately cause the shear displacement to rise and this excessive deformation contributes to tendon failure in more tension rather than in shear (Figure.7).

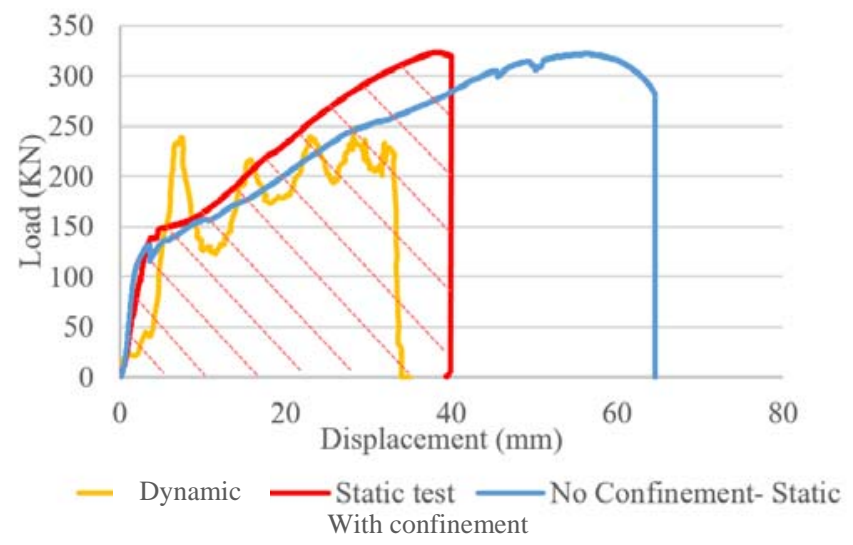

Fig. 6. Test 2 Load- Displacement results and absorbed energy 

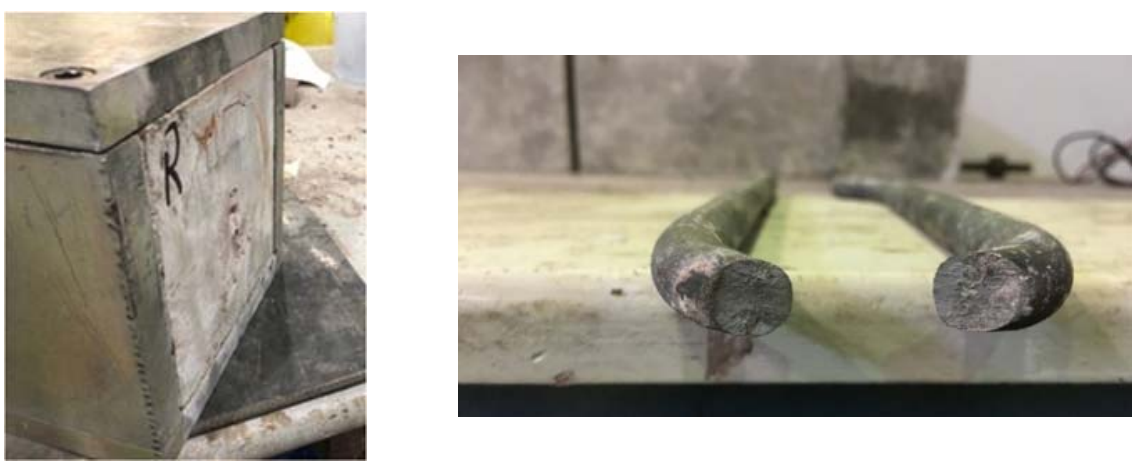

Fig. 7. Test 3- Sheared surface of $16 \mathrm{~mm}$ rock bolt in a confined concrete

\subsection{The effect of friction}

The first generation of double shear box (MKI) is not frictionless, meaning that the friction is actively effective during the experimentation of tendon strength subjected to shearing. Therefore, the peak shear load is not the actual maximum shear load spent on tendon shearing rather it is attributed to the combination of shear load as well as the amount of load required to overcome the concrete joints face friction. A mathematical equation, based on MohrCoulomb and Fourier series system, was developed to calculate the friction force between the sheared joint faces of the host medium (Aziz, et al. 2015).

$$
\tau_{p}=\left(\frac{a_{0}}{2}+\sum_{n=1}^{3}\left[a_{n} \cos \left(\frac{2 n \pi \frac{T}{2 \pi} \cos ^{-1}\left[\frac{-4 a_{2}+\sqrt{16 a_{2}-48 a_{1} a_{3}+144 a_{3}^{2}}}{24 a_{3}}\right]}{T}\right)\right]\right) \tan (\varphi)+c
$$

where $\tau p$ is the shear stress, $C$ is cohesion, $\tan (\varphi)$ is the angle of friction, an is Fourier Coefficient, $n$ is the number of Fourier Coefficient, which varies between 0 and 3 and $T$ is the shearing force travel, which is the characteristics of the shearing machine. Aziz, et al., (2015) found that $30 \%$ of the total shear force was spent on overcoming the friction between the shear joints. Aziz, et al., (2016) verified the effect of the equation with experimental test results. According to the outcome of the current research experiment, the dynamic shear load of rock bolt is equivalent to its static double shear load when the effect of friction is removed. The assumption is that when the specimen is subjected to dynamic double shear load the effect of friction becomes negligible because the friction is a time dependent factor and the impact load occurs in a fraction of a second, therefore the time effect can simply be considered ineffective. As a matter of fact, this study verified the validity of the MohrCoulomb and Fourier series above stated equation.

Also, the $30 \%$ effective friction can also be verified by the absorbed energy of the system calculated from the load-displacement graph. It can be claimed that the absorbed energy, calculated from the drop test, is close to pure shear capacity of the rock bolt. The static absorbed energy for test 3, Test 4 and Test 5 of $10.57 \mathrm{~kJ}, 11.26 \mathrm{~kJ}$, and $13.07 \mathrm{~kJ}$ respectively, while the dynamic absorbed energy, as calculated from the Load-displacement graph of 7.12 $\mathrm{kJ}, 7.61 \mathrm{~kJ}$, and $8.55 \mathrm{~kJ}$ of almost $70 \%$ of that from the static test (Figure. 8).

It is worth noting that dynamic testing of tendons can also be used for the study of ground reinforcements in areas prone to seismic activates and rock bursts, which is the current focus of research interest in coal mines of Australia and USA. 
Test 3

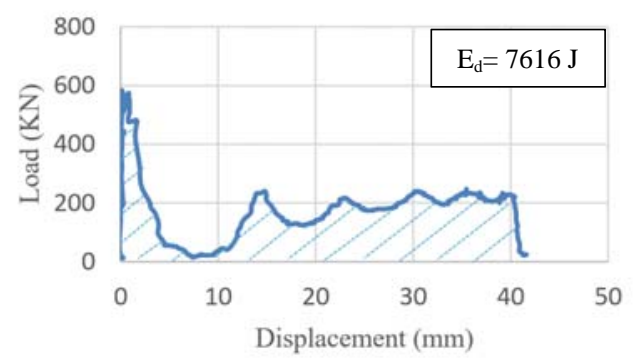

Test 5

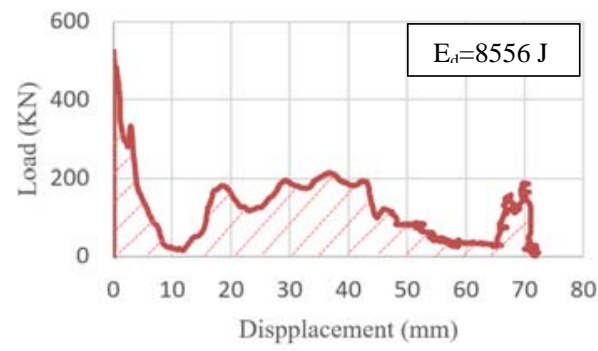

Fig. 8. Load - Displacement in Dynamic test

\section{Conclusions}

The internal confinement for the current experimental research has proven to be effective methods, as it improves the strength of the host medium, which eventually leads to the tendon failure in more shears rather than in tension regardless of the effect of friction.

The dynamic impact test results have verified the credibility of the Mohr-Coulomb and Fourier series equation in correctly estimating the proportion of the applied shear load spent on overcoming joint faces friction and to simulate the shear strength of bolted concrete blocks.

\section{References}

1. E. Villaescusa, A. Thompson, and J. R. Player, Dynamic testing of ground support systems, Phase I, MERIWA project No M3492 (2005)

2. $\quad$ M Plouffe, T Anderson, K Judge, Rock bolts testing under dynamic conditions at Cenmet- MMSL, in proc 6th international Symposium on ground support in mining and civil construction, TR Stacey and D F Malan(eds) 30th March -3rd April 2008, Cape town, South Africa the south African Institute of Min and Met, Johannesburg, 581 -395 (2008)

3. J. P. Player, E. Villaescousa, and A G. Thompson, Ground support in mining and underground construction, Proceedings of the fifth international Symposium on ground support 28-30 September, Perth (Ed: Ernesto Villaescusa and Yves Potvin.) 327-339 (2004)

4. N. Aziz, P. Craig, A. Mirzaghorbanali, H. Rasekh, J. Nemcik and X. Li, Experimental study and mathematical modelling. Coal Operators' Conference, Wollongong, University of Wollongong, 146-159. (2015b) http://ro.uow.edu.au/coal/559/

5. B. Stillborg, Experimental investigation of steel cables for rock reinforcement in hard rock. PhD Thesis (Lulea University, Sweden 1984)

6. $\quad$ British Standard BS7861-1, Strata reinforcement support systems components used in coal mines - Part 2: Specification for flexible systems for roof reinforcement (2009)

7. N. Aziz, A. Mirza, J. Nemick, X. Li, H. Rasekh and G. Wang, Experimental Study and Mathematical Modelling, Coal Operators' Conference, Wollongong, University of Wollongong, 32-39. (2016a) http://ro.uow.edu.au/coal/591/

8. N. Aziz, A. Mirza, J. Nemcik, H. Rasekh and X. Li, Experimental Study and Mathematical Modelling, Coal Operators' Conference, Wollongong, University of Wollongong, 24-31 (2016b) http://ro.uow.edu.au/coal/590/ 